\title{
A child with cancer: a family in crisis
}

\section{The parents, siblings, and the whole family require professional support}

The diagnosis of malignancy comes as a profound shock both to the affected child and the parents - a shock that spreads ripples of concern through the whole family and the surrounding community. Cancer is a major life threatening event that creates a great deal of uncertainty and insecurity among those most intimately affected. It is natural to think in the first place of the impact on the parents, ${ }^{1}$ but failure to take account of the consequences to others such as siblings, playmates, or grandparents is a failure to appreciate the extent of the problems posed. ${ }^{2}$

The priorities and perspectives of the parents may be altered quite radically overnight. They may be overcome by feelings of fear, anger, and guilt and may find it difficult to adjust to the substantial changes to their lives imposed by the events. Insecurity may develop quite suddenly, even in the most stable of relationships. Symptoms of anxiety and depression are very common, especially among mothers, and the obvious temptation for the general practitioner is to dish out pills in the hope of dulling the pain.. The family doctor needs to be sensitive to those parents whose symptoms become so crippling that they are prevented from functioning adequately: for them medication may be important even if it is only to deliver a decent night's sleep. The best solution for families, however, is for their problems to be handled by a group of professionals in whom they develop confidence and who are prepared to provide as much time and counselling as necessary.

At the time the diagnosis is made parents often find that they are separated for the first time in their married lives - just when they most feel the need for mutual support. Fathers may have to continue to work and may in addition take on unaccustomed sole responsibility for looking after the house and the other children. Meanwhile the mother and the affected child may be incarcerated in a regional centre, often a long distance away, where they spend abnormally long periods together, clinging to one another for support and developing an introspective isolation from the rest of the family. Pressure may be required-both on employers to persuade them of the need for fathers to spend time with the affected child and on hospital services to allow siblings access so that family unity is maintained.

Parents may need "permission" and encouragement at times to snatch a few brief moments together, but even then they may find it difficult to communicate at a level that satisfies their needs, and the loss of libido that often accompanies the psychological trauma does nothing to help matters. Couples who are accustomed to sharing their feelings have a great advantage over those who do not. There are particular problems for the strong, silent man who bottles up his feelings and cannot talk about them-and for his wife if she needs to pour out her grief about what is happening to their child and to talk through how she is going to manage. The legitimacy of these different coping mechanisms and the need for mutual understanding and forbearance may have to be pointed out by an acceptable third party.

Every family faces years of uncertainty about the eventual outcome of the illness, whatever the statistical probability of cure. There are also worries about the sequelae of treatmentthe price that may have to be paid for eradicating the disease. Even when treatment seems to have been successful, every blood test or $x$ ray film is a potential harbinger of doom, and it is important for clinicians to recognise the urgency with which the results of these "routine" tests are awaited. Families who have graduated to an annual review often report a week or more of short tempers and sleepless nights before an outpatient visit that is otherwise a welcome opportunity to see old friends. At this stage healthy teenagers may resent the reminder that there remains a question mark against their hard fought for "normality."

An important minority of children with cancer still succumb to resistant disease or die of the toxic effects of treatment. Much has been written in recent years about the care of dying children and their families, ${ }^{4}$ how to enable the families to participate as much as possible in terminal care, ${ }^{5}$ and how to manage the problems of bereavement..$^{6-8}$ The fact that the number of children who die has fallen substantially has not altered the need to provide expert coordinated care for them: efforts are being made further to improve this aspect of paediatric oncology practice.

The professional worker who is faced with an affected family should as a first priority assess the nature, the scope, and the magnitude of the problems that are likely to arise and should then evaluate the family's capacities to deal with them. It is helpful to draw up a list of those aspects with which they are likely to require the most help and to specify where such help might be available. Many voluntary agencies provide various means of help and support to such families, which may be invaluable and should not be ignored.

Another important task is to set up an effective communication network between all the disciplines concerned in the care 
of the family. ${ }^{9}$ Specific skills are required from general practitioners, a variety of hospital specialists, nürses, social workers, school and hospital teachers, and staff in other disciplines. Inevitably there will be areas of overlap in what each group legitimately regards as its territory; without effective communication and coordination the family members may well find themselves overburdened by too many people interfering in some aspects of their lives while in other critical areas they are left unsupported. This is particularly true of school, a most important aspect of the lives of both patients and siblings that has received insufficient attention in the past.

The prognosis for childhood malignancies has improved to a remarkable degree, but the impact of the diagnosis still resembles a sort of death sentence - death to life as it was for the affected family. The challenge to us as professionals remains, as before, to provide the sustenance that will help the family to survive this threat to its integrity. The psychodynamic theorists have done much to illuminate how we all have to learn to cope with necessary losses in our growth towards maturity, ${ }^{10-13}$ but the ordinary props of family life may well prove insufficient when families are faced with such an extreme challenge. Skilled professional support can help to cushion the impact and to sustain and nurture family members through this crisis in their lives, enabling them to emerge tempered but not fractured by the fire of the experience.

MARTIN G MOTT

Reader in Paediatrics (Oncology),

University of Bristol,

Royal Hospital for Sick Children,

Bristol BS2 8BJ

1 Hughes PM, Lieberman S. Troubled parents: vulnerability and stress in childhood cancer. British fournal of Psychotherapy (in press)

Schuler D, Bakos M, Zsambor C, et al. Psychosocial problems in families of a child with cancer. Med Pediatr Oncol 1985;13:173-9.

3 Mott MG. Caring for children with cancer. In: Wilkes E, ed. The management of the dying patient. Lancaster: MTP Press, 1982: 45-56.

4 Chambers EJ, Oakhill A, Cornish JM, Curnick S. Terminal care at home for children with cancer BrMed f 1989;298: 937-40.

Parkes CM. Bereavement: studies of grief in adult life. Harmondsworth, Middlesex: Penguin Books, 1975.

6 Lansky BS, Cairns GF, Stephenson L, Cairns NU, Weller E. Failure to thrive during infancy in siblings of pediatric cancer patients. Am F Pediatr Hematol Oncol 1982;4:361.

Lauer ME, Mulhern RK, Shchell MJ, Camitta BM. Long-term follow-up of parental adjustment following a child's death at home or hospital. Cancer 1989;63:988-994.

8 James JA, Harris DJ, Mott MG, Oakhill A. A paediatric oncology information pack for general practitioners. Br Med f 1988;296:97-8

Larcombe T, Walker J, Charlton A, Meller S, Morris-Jones P, Mott MG. The impact of cancer on return to normal schooling. $\mathrm{Br}$ Med $\mathcal{F}$ (in press).

Viorst J. Necessary losses. London: Simon and Schuster, 1986.

11 Bowlby J. The making and breaking of affectional bonds. I. Br f Psychiatry 1977;130:201-10.

2 Bowlby J. The making and breaking of affectional bonds. II Br $\mathcal{F}$ Psychiatry 1977:130:421-31.

13 Meadows AT, McKee L, Kazak AE. Psychosocial status of young adult survivors of childhood cancer: a survey. Med Pediatr Oncol 1989;17:466-70.

\section{Teaching medical students about alcohol}

\section{Could be integrated throughout the curriculum, but first the attitudes of teachers must change}

Despite the evidence that alcohol misuse damages health many doctors still seem unwilling to take a drinking history and feel unable to help patients change their damaging drinking habits. 12 "There seems to be an unspoken assumption that physicians should only concern themselves with the diseases caused by alcohol misuse" rather than the drinking itself. ${ }^{3}$ Several factors account for this reluctance, including lack of knowledge, embarrassment, and pessimism about the possibility of changing entrenched habits. Not least, how- ever, may be the doctor's own drinking habits and attitude towards alcohol. Many of these attitudes were formed at medical school, and, as discussed at a recent meeting run by the Royal College of Physicians of Edinburgh and the Medical Council on Alcoholism, may in turn affect the way that today's students are being taught about alcohol. ${ }^{+}$

On average, medical schools devote only about 14 hours of teaching to alcohol and drug misuse. ${ }^{5}$ More disturbingly, medical training seems to have a negative effect on attitudes towards alcohol abuse, students becoming less sympathetic and concerned during the years of clinical training. This may be due partly to the negative attitudes of senior clinical teachers towards patients with alcohol problems. Several medical students attending the meeting commented on their teachers' lack of interest in drinking histories they had taken and on their general dismissiveness towards patients with alcohol problems. There is ample evidence that these patients are unpopular with doctors in all specialties, including psychiatry. ${ }^{67}$ Non-psychiatrists still tend to view alcohol problems as principally the concern of psychiatrists, which may have the effect of marginalising their importance in general medical education. Thus training in alcohol and drug misuse is not seen as part of the core curriculum and attempts to improve the training meet obstacles in the negative attitudes of those who have the power to influence the curriculum.

If alcohol problems are to receive prominence in the training of doctors then more research is needed into methods of educating both undergraduates and, as importantly, their teachers. Favoured approaches include video practice, small group tutorials, and practical clinical experience, preferably over an extended period with selected patients. Medical students should also be encouraged to increase their awareness about their own drinking habits and acknowledge the difficulty they have in changing them. In this way the distinction between the patient and the carer would become blurred, improving students' insight into the difficulties patients have with alcohol problems. At a time of increasing technological development in medicine undergraduate training must not neglect the development of communication and counselling skills. Helping people to change habits associated with unhealthy lifestyles has become important in all medical practice.

At the meeting it was suggested that each medical school should make a designated teacher responsible for developing integrated teaching about alcohol and other forms of substance misuse within the curriculum and for monitoring the impact of these changes. Other suggestions were to find ways of providing continuity of education between undergraduate and postgraduate training and to liaise closely with nonmedical disciplines to reinforce training in a team approach to alcohol misuse.

We know that the medical curriculum is overcrowded and faces competing demands for time. The profile of alcohol and substance misuse could, however, be raised without making inroads into other clinical topics simply by ensuring that its importance was emphasised at every opportune stage in the undergraduate experience. ${ }^{8}$ The World Health Organisation has recently examined ways in which this subject might be integrated into the medical curriculum and has provided guidelines for teaching. ${ }^{9}$ The health consequences of alcohol misuse are protean. Hence there will never be any difficulty in obtaining enough clinical examples to underscore the importance of asking about alcohol as part of taking a medical history.

Consultant Psychiatrist,

Royal Edinburgh Hospital,

Edinburgh EH10 5HF 